\title{
STUDY ON LIGHTING PARAMETERS OF AUDIBLE AND VISUAL WARNING DEVICES USED BY THE POLICE OF THE CZECH REPUBLIC
}

In the article, the authors are concerned with the lighting parameters of audible and visual warning devices used by the Police of the Czech Republic in reaction to European legislation on this issue. The aim of this article is to explain the principle itself and the properties of radiation of light with its photometric specifications that can be evaluated and perceived by human eye, including subsequent negative effects on human health. The article presents a study of evaluation of measured values of luminance, luminous intensity and other photometric quantities of selected audible and visual warning devices used by the Police of the Czech Republic.

Keywords: Police of the Czech Republic, photometric quantities, lightbars, beacons, audible and visual warning device

\section{Introduction}

Recently, special audible and visual warning devices (beacons, lightbars) of the Police of the Czech Republic, and also of the other emergency services all over the world have been discussed widely, above all in relation to the colour of light emitted and the continuous development in the area of used luminaires and materials of which these luminaires are made with the aim to use electricity more effectively, to improve visibility in terrain and to achieve longer life, similarly to the other branches of industry. These are the main reasons why the authors of this article are concerned with lighting parameters of police audible and visual warning devices of types used in many cases by the other safety and security services.

The problems of audible and visual warning devices used in the Czech Republic and in the world and the comparison of them have not been dealt with comprehensively yet; greater attention should be paid to these questions owing to their importance for the informing of citizens in critical situations, e.g. when human lives have to be saved. From the point of view of assessment of lighting parameters, the knowledge of the general physical principle of propagation of visible light and of photometric quantities, which are of importance to the comparison of photometric characteristics of several types of audible and visual warning devices with each other, is significant. An integral part of assessment is also the knowledge of the area of vision physiology and of negative health effects of inadequate exposure of human organism to the radiation of visible light. The assessment also has to respect the requirements of relevant valid legislation and international standards. [1-12] Moreover, the proper verification and the evaluation of photometric quantities have to be in accordance with the requirements of relevant international standards. All these aspects were taken into account when dealing with the joint project on the basis of cooperation between the Faculty of Safety Engineering, VSB - Technical University of Ostrava and the Regional Headquarters of Police of the Moravian-Silesian Region of Police of the Czech Republic (henceforth referred to as PCR). The project was simultaneously directed towards the acoustic parameters of audible and visual warning devices of PCR and was implemented in the years 2009 and 2010. Its results form the content of two Master's theses thematically focused like that; the authors being students in the field of Safety Engineering of Faculty of Safety Engineering of VŠB Technical University of Ostrava.

\section{Properties of Visible Light in Relation to Human Perception of Audible and Visual Warning Devices}

Light composed only of waves having one wavelength or little different narrow-band wavelengths is perceived by human eye as coloured light. Visible radiation is part of a spectrum of non-ionizing radiation in the range from $3.9 \times 1014 \mathrm{~Hz}$ to $7.9 \times 1014 \mathrm{~Hz}$.

The spectrum is a physical card of colours produced by the decomposition of white light. The colour stimulus is radiation characterised by a certain spectral composition and luminous flux or luminance, which penetrates into the observer's eye and induces a colour sensation. The same visual perception which would be created by a single colour of the spectrum can be obtained by mixing two or more other spectral colours that do not contain the wavelength of the resultant colour at all.

\footnotetext{
* Martin Hrinko ${ }^{1}$, Svetla Fiserova ${ }^{2}$

${ }^{1}$ Police of Czech Republic, KRP Moravskoslezskeho kraje, Ostrava, Czech Republic, E-mail: martin.hrinko@seznam.cz

${ }^{2}$ VSB-TU Ostrava, Faculty of Safety Engineering, Ostrava - Vyskovice, Czech Republic
} 
Colour properties of light are called chromaticity; it is given by the spectral composition of radiation emitted by a source and is usually given in trichromatic coordinates. A typical example is the observation of coloured signal lights that are often perceived as point sources. In the trichromatic system, the fact that by additive mixing three measured colour stimuli a perception of any colour can be obtained is used as a basis [13].

Luminous intensity I [cd] is the fundamental photometric quantity expressing the property of a light source (point). It describes the spatial distribution of the luminous flux of a source or a luminaire. For a point source, the luminous intensity is defined as a ratio of the luminous flux emitted by the source in an elementary solid angle containing the given direction to the size of this solid angle. As a point source almost every luminaire the largest dimension of which $a$ is negligible in relation to the distance $l$ between the source and the check point, $l \geq 10 a$, can be regarded. Luminous intensity distribution curves are sections through the surface of luminous intensity distribution that run through the light centre of the luminaire. The surface of luminous intensity distribution is the surface determined by the endpoints of all luminous intensity vectors that start at the light centre of the luminaire. In the case of point sources of light, the distribution of luminous flux can also be obtained from luminous intensity distribution curves. In catalogue cards, luminous intensity distribution curves are plotted in polar or rectangular coordinates.

Luminance $\mathbf{L}$ [cd. $\mathbf{m}^{-2}$ ] is determined as the luminous flux that is emitted from, impinges on or passes through the elementary surface $d S$ in relation to the projection of the elementary surface $d S$ onto a plane perpendicular to the direction given by the axis of elementary solid angle $d$.

Radiation in the visible part of the spectrum is absolutely necessary for life, but the high intensity of light may damage the retina. The effects can be, depending on the size of exposure, desirable for as well as harmful to the organism. By radiation incident on the retina two types of reactions occur, namely photothermal and photochemical. The photothermal reaction takes place after heating the retina by $10{ }^{\circ} \mathrm{C}$; photochemical damage appears after the incidence of intensive blue-light radiation on a photoreceptor that will die. A similar phenomenon may occur after illumination of the eye with a white LED, which is mostly composed of intensive blue and luminophor. A possibility of eye damage is however lower, because luminophor emits light in the range of maximal sensitivity of the eye, and after illumination, the eye adapts quickly by changing the diameter of aperture of the iris leading to a 16-fold decrease in the area, which will considerably reduce the amount of light on the retina. To the blue colour the eye is minimally sensitive, and thus the iris reacts minimally. Like other forms of energy, the nonionizing radiation is also able to react with biological systems. The effect depends on many physical parameters, especially on the wavelength of radiation that determines the place where the radiation can be absorbed, and on the intensity of radiation that is crucial to the degree of radiation effect [13].

\section{Audible and Visual Warning Devices from the Point of View of Czech Legislation}

The most significant law regulating the use of audible and visual warning devices in the CR is Act No. 361/2000 Coll., on road traffic (Road Traffic Act). With a special audible warning device supplemented with a special blue warning light, the following vehicles can be equipped [3]:

- those of Ministry of the Interior used by the police and marked according to a special legal regulation

- of Prison Service

- of Military Police marked according to a special legal regulation

- of Municipal Police that are determined by the municipality concerned

- of Fire Rescue Service

- of Mine Rescue Service

- of gas breakdown services

- emergency medical services and transport of sick and injured persons and that of expectant mothers

- of armed forces used with military rescue forces for the performance of humanitarian tasks of civil protection

- of customs authority marked according to a special legal regulation.

It is necessary to emphasise that in the CR merely blue beacons without a possibility of combining with other colours are allowed in all vehicles of so-called rescue and security services.

The homologation of audible and visual warning devices used by the Police of the CR is carried out at the Electrotechnical Testing Institute in accordance with the requirements of the binding European EEC Directive No. 65.

The other principles for the use of audible and visual warning devices by Czech policemen follow from a binding instruction of the Police President from the year 2002. The instruction determined uniform principles for the use of audible and visual warning devices. In the instruction of the Police President, lightbars and beacons are regarded as special audible and visual warning devices. The use of a special audible and visual warning device is understood as giving a blue light signal, which can be supplemented with a special audible warning signal. Both can be used in combination with a public address system. The lightbar/beacon for this purpose is a detachable or attached device mounted on a vehicle of the Police of the CR. The lightbar/beacon can be used merely in the course of fulfilling tasks associated with the performance of special duties; police vehicles having the right of way.

The majority of vehicles of the Police of the CR use audible and visual warning devices supplied by the company Zdenek Holomy Electronics (henceforth referred to as company). The assortment of products offered by the company on the market for various kinds of sources of light is wide. For this reason, for every source of light the authors selected one representative of the devices that use this source. The first device is designated VNK 530 (incandescent lamp set) - Fig. 1. The type of the second is VSK 012F (discharge lamp set) - Fig. 2. Another flashing lightbar is desig- 


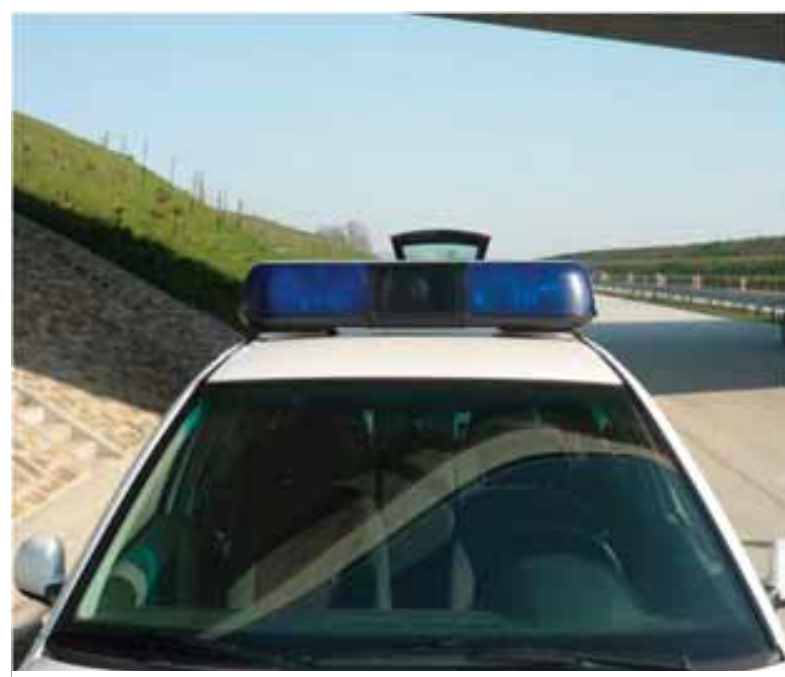

Fig. 1 Lightbar VNK 530

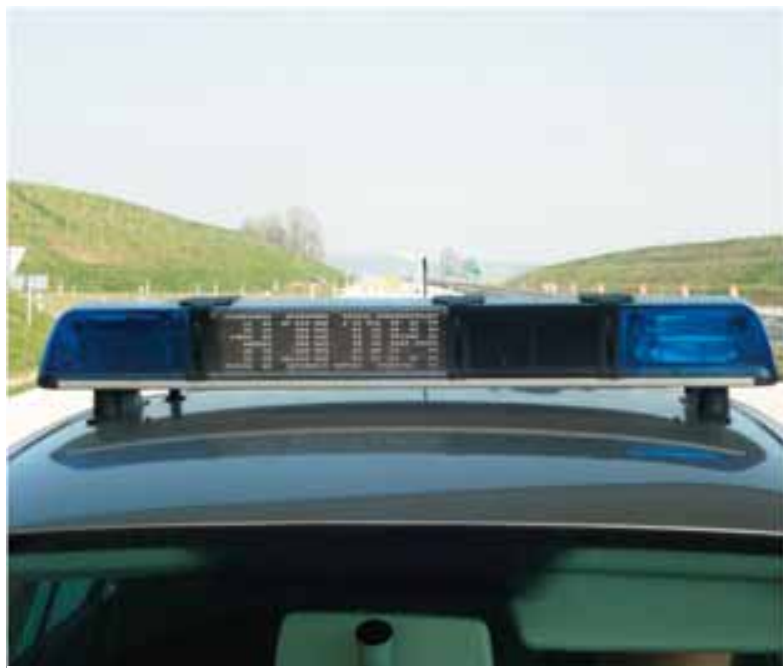

Fig. 3 VSL 012FL

nated VSL 012FL (linear discharge lamp set) - Fig. 3, and a lightbar with LEDs - diode lightbar VSL 012LV - Fig. 4. In individual types, a large number of configurations of the light source itself, an acoustic device and additional word markings, such as POLICIE, STOP, and others exist. For this reason, the authors of the article always supplemented the selected device with a figure showing a corresponding measurement configuration. The presented devices are compatible as far as the control device, e.g. AZJ $530 \mathrm{~A} \mathrm{CO}$, is concerned [14].

\section{Assessment of Lighting Parameters of Audible and Visual Warning Devices}

In the case of all four above-mentioned sets, screening measurements of selected photometric quantities were made using professional measuring devices in the framework of the implemented

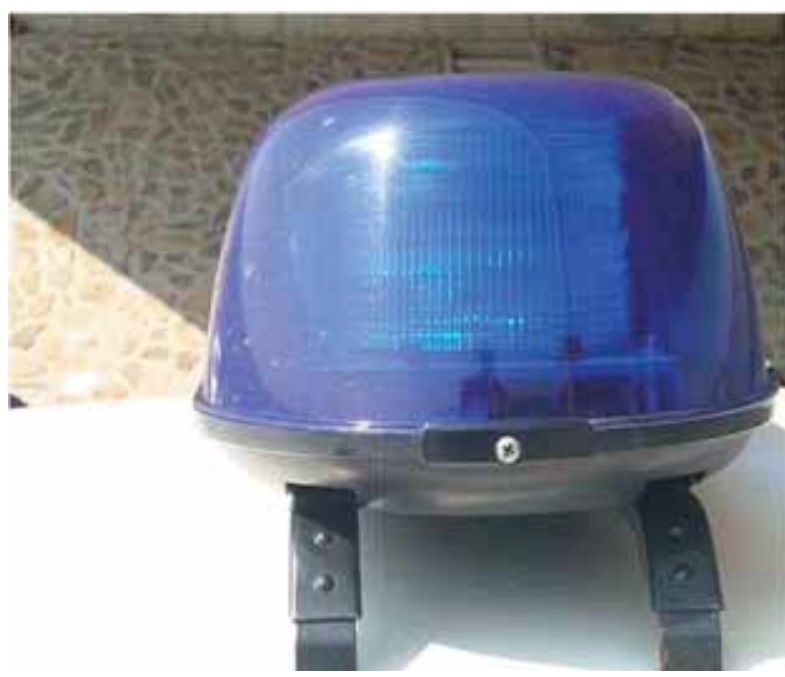

Fig. 2 Beacon VSK $012 F$

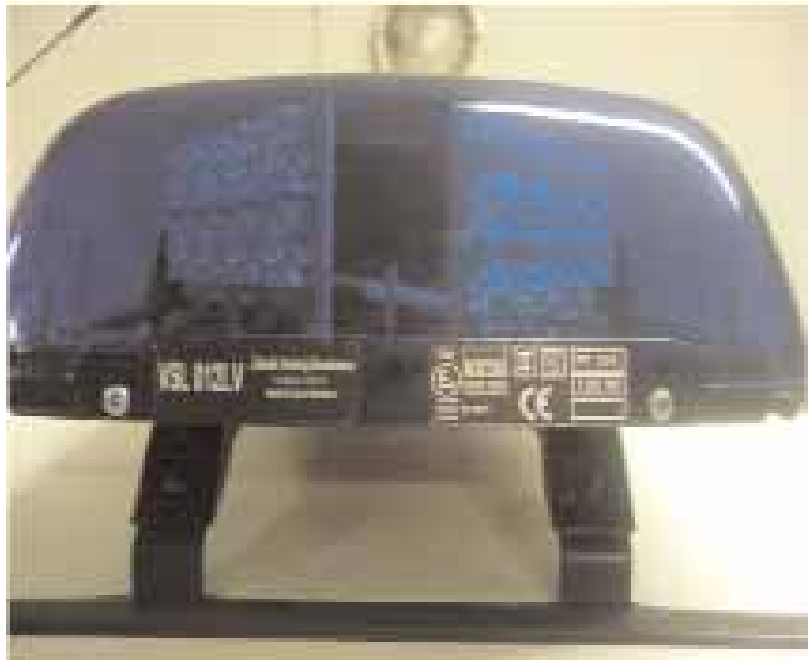

Fig. 4 VSL 012LV

study, namely luminance, illuminance (instantaneous luminance) and flash frequency. Luminance measurement was carried out beyond the requirements of EEC Directive No. 65. Additionally, measurements of trichromatic components and colour coordinates were taken merely with the selected lightbars and beacon.

The measurements were made both in real conditions of operation, i.e. in the shadow of a bridge structure in a D1 motorway segment closed to the traffic, in a darkened room and in a light laboratory in the HARD building of Faculty of Electrical Engineering and Computer Science of VSB - Technical University of Ostrava.

For the screening measurements, standard requirements of relevant international standards were satisfied; for technical reasons, it was not possible to take all measurements as prescribed by the EEC Directive No. 65. 
With reference to the fact that the sets are different in the used light source and design, the comparison of these sets with each other is difficult. Photometric specifications and other technical parameters, such as set power input, etc. can be quantitatively compared. The compared photometric specifications are based on the requirements of EEC Directive No. 65. In the case of approved types, they are above all luminous intensity, colour coordinates and flash frequency. Beyond the Directive, luminance measurements were made with all types of the given audible and visual warning devices under the same conditions. All measurements should be carried out in dark areas without a possibility of influencing by stray light. The measurements were always done on one optical unit (i.e. one beacon in the lightbar) owing to the symmetry of the set. There are certain deviations in photometric properties between the same types manufactured in series as permitted by the EEC Directive No. 65

For the measurement of trichromatic components a chromameter CS-100A from the company Minolta was selected. The chromameter is a professional measuring device for measuring the integral colour characteristics of light; likewise a luminance meter, it measures the properties of light in a delimited solid angle - aperture of the objective. In addition to the luminance in $\mathrm{cd} \times \mathrm{m}$ 2 , it can measure the colour coordinates $\mathrm{x}, \mathrm{y}$. Besides the absolute measurements also different values, i.e. those related to the value stored in the memory, can be measured. The device communicates with a PC by means of a serial interface and is able to print directly the measured data on a special printer. The standard measurement angle is $1^{\circ}$, which corresponds to the solid angle of about 0.00024 sr. The uncertainty of the measurement of colour coordinates ( $\mathrm{x}$, $y): \pm 0.004$. In the course of last measurement, the colour coordinates were measured using a filament spectrometer AvaSpect 2048-USB1. For the measurement of luminance, a luminance meter LS 100 from the company Minolta was selected. The luminous intensity was measured using a universal measuring device Almemo 2590-4S from the manufacturer Ahlborn, with which a photocell FL A613-VL (sensor of illuminance with a range of $26000 \mathrm{~lx}-$ the manufacturer specifies the accuracy as $5 \%$ of measured value) was used. The flash frequency was determined by visual observation and recording of the number of flashes within a certain time or by recording the behaviour of luminous intensity with a luxmeter, where the development of flash peaks of beacons with time can be seen. For the measurement of the on time of the flashes, a universal measuring device Almemo 2590-4S was used [13].

The measurement uncertainties can come from the comparison of photometric properties of the same special warning devices, their deviations from the approved type in the case of manufacturing in series; the uncertainty is further given by the precision of measuring devices, by human errors (location of the device during measurements, misread values, unsuitably selected measuring range), crucial changes in environmental conditions (temperature, pressure, humidity, undesirable substances in environments, and others), interference and miscalibration. A change in supply voltage of the set and the on time of the flash, which influences the response of measuring and evaluation unit of the device, will play a great role. Measurement results will also be influenced by the reflectance of the background in the room or space where measurements will be taken. As for the measuring devices, the influence of a systematic error, i.e. uncertainty of the type $\mathrm{B}$, is considered.

\section{Measurement Results and Discussion}

The measurements were carried out repeatedly under all the above-mentioned conditions of measurement from the $16^{\text {th }}$ April 2009 to the $30^{\text {th }}$ March 2010. The luminous intensity was recalculated according to the square law: $I=E \cdot r^{2}$. Values of luminous intensity and luminance are rounded to integers to obtain clear results. The luminance of areas of equal size measured at any distance from the areas should be the same. A difference in luminance measured at a distance of $1,014 \mathrm{~mm}$ and that of $2,000 \mathrm{~mm}$ is caused by measuring a larger part of luminaire area where not only a light active part of the luminaire might be measured. From a one minute record, the maximum value of instantaneous luminous intensity of every set was always selected. In the case of luminance of the sets, the greatest value of ten measured values was selected. Maximum measured values of selected photometric quantities are compared in Table 1 which summarises the results of all taken measurements under the above-presented conditions on four various types of audible and visual warning devices.

Maximum obtained values of photometric quantities

Table 1

\begin{tabular}{|c|c|c|c|c|}
\hline $\begin{array}{c}\text { Type } \\
\text { of set }\end{array}$ & $\begin{array}{c}\text { Maximum } \\
\text { instantaneous } \\
\text { luminous } \\
\text { intensity } \\
\text { flash } \\
\text { frequency }\end{array}$ & $\begin{array}{c}\text { Measured } \\
\text { value of lumi- } \\
\text { nance } \\
\text { measured at } \\
1014 \mathrm{~mm} \\
\text { distance }\end{array}$ & $\begin{array}{c}\text { Maximum } \\
\text { value of lumi- } \\
\text { nance } \\
\text { measured at } \\
2000 \mathrm{~mm} \\
\text { distance }\end{array}$ \\
\cline { 2 - 5 }$\left[\mathrm{cd} / \mathrm{m}^{2}\right]$ & {$\left[\mathrm{cd} / \mathrm{m}^{2}\right]$} \\
\hline VNK 530 & $6774 \pm 389$ & 0.9 & $18120 \pm 364$ & $16740 \pm 337$ \\
\hline VSK 012F & - & 2.5 & $11680 \pm 236$ & $10330 \pm 209$ \\
\hline VSL 012FL & $4184 \pm 209$ & 2 & $12460 \pm 251$ & $11340 \pm 229$ \\
\hline VSL 012LV & $261 \pm 13$ & 2.85 & $>49990$ & $33210 \pm 666$ \\
\hline
\end{tabular}

The observed values of photometric quantities of various types of audible and visual warning devices used on vehicles of the Police of the Czech Republic and experience achieved when dealing with the project are a basis for the following summary.

The required parameters of effective luminous intensity can be obtained either by extending the on time of the flash to the maximum possible admissible value, or by increasing the instantaneous luminous intensity at a relatively short on time of the flash. During outdoor measurement, the highest instantaneous luminous intensity was achieved by the lightbar VNK 530 - incandescent lamp set, namely $6774 \pm 339 \mathrm{~cd}$. At the distance of $1014 \mathrm{~mm}$, the luminance was $18120 \pm 364 \mathrm{~cd} / \mathrm{m}^{2}$. Measurements in outdoor spaces were considerably affected by environmental conditions, especially by daylight radiation and other sources of light and reflections typical 
of real conditions. More accurate results would be achieved by the complete elimination of stray light and reflections. In the course of measurements in the darkened room, the highest luminance was achieved by VSL 012LV diode lightbars with which the measuring range of luminance meter was exceeded. The advantage of sets using the LED technologies is the colour of emitted light that does not depend on the passage through a filter leading to the colouring of emitted light. With regard to the high values of luminance that may be in the case of exposed persons a source of glare, eye protection should be considered. For eye protection during measurements and repairs it would be suitable to use absorption colour filters and/or shields in the case of discharge lamp sets and above all in the case of efficient sets utilizing LED technologies. Attainable luminous intensities are so high that there is a need to observe the limit of maximum values prescribed by the EEC Directive No. 65 , because they may be exceeded when the main "beacon" is used with additional lights, which results in the glare of drivers mainly at night [13].

Measurements done in the field, in the darkened room and the light laboratory using stationary measuring devices are, in spite of their relatively large extent, the basis for the further verification of photometric properties of audible and visual warning devices used by the Police of the CR and for the comparison of lighting parameters of sets utilizing either a combination of blue and red colour or only the red colour. By combining the flashes of the device emitting blue and red light, effective visibility in fog and sunny weather could be achieved.

\section{Conclusion}

The European EEC Directive No. 65 allows the use of the red colour of light. The red colour of light is generally used to indicate a ban, emergency, stop, failure or any danger, and from the point of view of meaning of colours of visual signals, is superior to the blue colour of light. The blue colour draws extraordinary attention, indicates the right of way and actions leading to solving some difficult situation. The colour of the light emitted by police "lightbars/ beacons" is prescribed merely by national legislation. For instance, in Slovakia vehicles having the right of way can use special warning lights of red or blue colour or of their combination. In the CR the public is accustomed to the use of this colour of light emitted by lightbars. The selection of the colour of light of lightbars is a very sensitive issue. If merely the red colour of police lightbars was used, the observer could confuse these devices with the brake lights of cars. However, by a suitable combination of flashes of the device emitting blue and red colours of light, effective visibility in fog and sunny weather could be achieved. Moreover, the red colour of light or the blue colour of light could be used depending on the circumstances of use of the audible and visual warning devices according to the severity of situation being solved.

The issue of photometric properties of visual and audible warning devices is really topical in connection with the continuous development of new technologies in the area of used materials, luminaires and energy sources as well.

\section{References}

[1] CSN EN 62 471: Fotobiologicka bezpecnost svetelnych zdroju a soustav svetelnych zdroju [Photobiological Safety of Lamps and Lamp Systems], Prague : Czech Standards Institute, 2009.

[2] CSN EN 60 073: Zakladni a bezpecnostni zasady pro rozhrani clovek - stroj, znaceni a identifikaci - Zasady kodovani sdelovacu a ovladacu [Basic and Safety Principles for Man - machine Interface, Marking and Identification - Principles Media Encoding and Drivers]. Prague : Czech Standards Institute, 2003.

[3] CSN EN 13 032-1: Svetlo a osvetleni - Mereni a uvadeni fotometrickych udaju svetelnych zdroju a svitidel - cast 1: Mereni a format souboru udaju [Light and Lighting - Measurement and Reporting Photometric Data of Lamps and Luminaires - Part 1: Measurement and Data File Format], Prague : Czech Standards Institute, 2005.

[4] CSN EN 981+A1: Bezpecnost strojnich zarizeni - Systym akustickych a vizualnich signalu nebezpeci a inform. signalu [Safety of Machinery - Systym Acoustic and Optical Signals Danger and Inform. Signal], Prague : Czech Standards Institute, 2009.

[6] CSN 36 0010: Mereni svetla [Measurement of Light], Prague : Czech Standards Institute, 1996.

[8] Zakon c. 56/2001 Sb., o podminkach provozu vozidel na pozemnich komunikacich [On Conditions of Operation of Vehicles on the Road].

[9] Zakon c. 361/2000 Sb., o silnicnim provozu [on Road Traffic (Road Traffic Act)].

[10] Narizeni vlady c. 1/2008 Sb., o ochrane zdravi pred neionizujicim zarenim [On Health Protection Against Non-ionizing Radiation].

[11] Narizeni vlady c. 361/2007 Sb., kterym se stanovi podminky ochrany zdravi pri praci [Laying Down the Health Conditions at Work].

[12] Vyhlaska c. 341/2002 Sb., o schvalovani technicke zpusobilosti a o technickych podminkach provozu vozidel na pozemnich komunikacich [Approval of Technical Skills and Technical Conditions of Operation of Vehicles on Roads].

[13] HOVORKA, V.: Svetelne parametry majaku Policie CR [Illuminated Beacons Parameters Police of the Czech Republic], Ostrava, DP Bezpecnostni inzenyrstvi, Fakulta bezpecnostniho inzenyrstvi, VSB - TU Ostrava 2010.

[14] Svetelne soupravy [Light Kits] [cit. 2010-21-01]. In WWW: http://holomy.cz/rampy.html. 